DOI: $10.5216 /$ racs.v4.59295

\title{
El libro Milpero
}

\author{
Juan Guzmán Gutiérrez ${ }^{1}$
}

\section{RESUMEN}

El texto presenta un libro milpero, suporte que expresa actividades del proyecto Milpas Educativas. Asi se muestra un poco de la vida y algunas actividades educativas relacionadas al territorio en una comunidade maia del sur de México.

Palabras Clave: Milpas educativas. Contexto. Conocimiento.

\section{O livro Milpero}

\section{RESUMO}

O texto apresenta um livro milpero (livro vivo), suporte que expressa atividades do projeto Milpas Educativas. Nesta direção, mostra-se um pouco da vida e algumas atividades educativas relacionadas ao territótio em uma comunidade maia do sul do México.

PALAVRAS-CHAVE: Milpas educativas. Contexto. Conhecimento.

Kaxlan - es una expresión en la lengua tzeltal, para describir a los mestizos descendientes de la sociedad colonizadora.

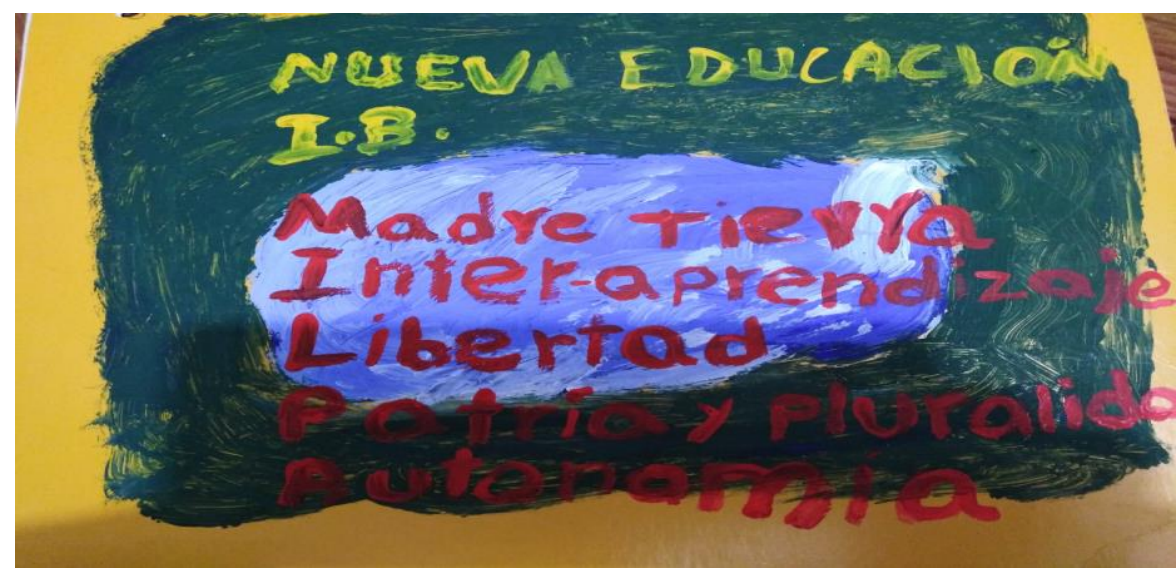

\footnotetext{
${ }^{1}$ Educador independiente. Unión de Maestros de la Nueva Educación para México (UNEM). Povo Tzeltal. San Jose Pathuitz, Chilon, Chiapas, México. E-mail: chawukil@ hotmail.com.
}

Dossiê Práticas de bem viver: diálogos possíveis entre o Núcleo Takinahakỹ e Milpas Educativas 


\section{Introducción}

La comunidad de San José Pathuitz fue fundada en los años 60 por un grupo de personas, en su mayoría tzeltales, bachajontecos, chiloneros, y otras personas procedentes del pueblo chol, náhuatl, en tiempos de la crisis política, económica y social, y bien recuerdan que fueron a buscar el futuro. En la plena selva la vida no era tan difícil, había riesgos por los animales salvajes, pero es parte de la vida, vivir en el monte implica mucho trabajo.

La mayoría de los habitantes se dedican a la actividad agrícola, ganadería, crianza de aves de corral, porcinos, ovejas. Básicamente son actividades que solventan la subsistencia familiar dentro del territorio, también se han apropiado de actividades alternativas, como la apicultura, huertos, actividades que no dañan el territorio. Por otra parte también se practica una agricultura modernizada, se aplican fertilizantes y herbicidas.

Un anciano me contó que anteriormente cuando recién llegaron se trabajaba principalmente en hacer la milpa: la fase del trabajo es rosar, tumbar, quemar y sembrar. En la milpa se producía muchos alimentos naturales, en ciertas temporadas nacen las verduras silvestres, se recolectaban los alimentos en la naturaleza o en el monte, la naturaleza producía por si sola una gran cantidad de alimentos, el chapay se daba en los meses de febrero y marzo, se recolectaba el ax, que es una fruta que se come, el huapaque, en temporadas de la cosecha de maíz se aprovechan de hacer trampas para comer carne de tepescuintle. La vida en el monte es muy bondadosa cuando se aprende a vivir con ella.

La vida más cercana a la naturaleza contiene una gran complejidad de saberes, valores, cosmovisiones del mundo en relación con las conductas o comportamientos sociales. Se ponen en práctica infinidades de actividades para satisfacer sus necesidades básicas, como la alimentación, salud o curación, artefactos, eventos sociales o ceremoniales.

El trabajo campesino era producir el sustento básico de la familia, recordemos que anteriormente estábamos incomunicados, lejos de la vida kaxlan, por eso la producción agrícola cumplía el objetivo de la milpa tradicional, cultivar básicamente el maíz, calabaza, frijol, yucas, camotes, yame, plátano, complementándose en la caza, pesca y recolección en el ambiente natural, se realizan de acuerdo al ciclo natural.

Ahora se escucha feo decir, que somos campesinos, milperos, cuando en realidad hay escases de alimentos, ya casi todo se compra, muy poca gente se dedica al trabajo de la milpa para producir sus alimentos básicos. 
Antes, en los años 70's era muy distinto, la mayoría de la gente se dedicaba a la agricultura, cultivando la milpa, así se produjo mucho maíz y logramos comprometer al gobierno de hacer una bodega de maíz para venderlo directamente con el gobierno a través de la conasupo o COPLAMAR. Pero todo cambió porque el mismo gobierno impulso el desarrollo económico, ofreció crédito ganadero en los Ejidos con el "ban rural" en común acuerdo con La Reforma agraria para desforestar las parcelas y sembrar pastos haciendo potrero, así fue como una cuarta parte de los ejidos se hicieron ganaderos deteriorando sus tierras por el dinero, entrando entonces la maldición, crecieron económicamente los ganaderos pero ya no tenían espacios para sus milpas y se vieron en la necesidad de comprar maíz, en sustento básico de la alimentación.

Después el gobierno ofreció apoyos al campo con el Desarrollo Rural, SEDESOL, regalando semillas mejoradas, híbridos, fertilizantes, con asesorías de los agrónomos, con la intención de impulsar el desarrollo económico, pero muy pronto se vieron los resultados: fracasaron muchos agricultores, la milpa de esa variedad de maíz no está adaptada al ciclo climatológico de las lluvias, se pudrieron las semillas de las mazorcas del maíz antes de cosechar, y algunos que se lograron cosechar se picaron rápido, se dieron cuenta que estos maíces no se podían guardar en las trojas.

Al cultivar el maíz hibrido o transgénico hizo que se extinguieran algunas variedades del maíz nativo, el sak wuaj, bak k’anal, yax te' ixim, entonces la gente se dió cuenta que el gobierno lo estaba haciendo a propósito, algunos recuperaron sus semillas, tratando de cultivar la milpa de forma tradicional, pero la nueva generación de la sociedad han preferido trabajar de forma mixta, cultivan semillas criollas pero le aplican agroquímicos para controlar la hierba o el monte, como una forma para poder tener rendimiento económico, ya que así lo pueden vender, ya no es únicamente para el autoconsumo, se comercializa con los coyotes o intermediarios que llevan a vender donde no hay maíz, en las zonas ganaderas y cafetaleras.

Actualmente los jóvenes ya no quieren trabajar en la milpa, prefieren practicar el deporte, migrar a las grandes ciudades en busca de empleos, solamente están pensando en ganar dinero, aspiran estudiar alguna carrera en las escuelas públicas o privadas, y para hacerla se van cada vez más lejos de su territorio, se enajenan de la cultura comunitaria, aprenden a ser más individualistas, se apropian de un sistema de pensamiento de la corriente positivista y liberal, si al caso regresan a su comunidad conciben el territorio desde una visión capitalista. 
Entre toda esta situación crítica del trabajo del campo, estamos tratando de resistir recuperando y valorando los saberes tradicionales de la milpa, también los saberes científicos que buscan promover el estudio de la permacultura, es decir, el trabajo del hombre más relacionado a la naturaleza.

Nuestra familia es campesina, nos heredaron la cultura de aprender haciendo, y entender el mundo desde nuestra experiencia con el trabajo, la memoria histórica que se relata en distintos momentos propicia la reflexión sobre la interconexión del hombre con la naturaleza y el inframundo. El elemento esencial del hombre y de los pueblos indígenas es nuestra historia, el origen de nuestra civilización como hombres y mujeres del maíz.

Estamos reivindicando nuestros derechos como descendientes de los primeros habitantes de estas tierras. En 1995 se organizan un grupo de jóvenes promotores de educación comunitaria, con el propósito de desarrollar un nuevo modelo educativo intercultural bilingüe, que garantiza el derecho de los pueblos mayas en una participación activa de la construcción de una Nueva Educación para México que responda al desarrollo del conocimiento de las lenguas y la cosmovisión indígena, que promueva el desarrollo económico, político y cultural, y asegure su libre determinación al nivel local, regional y nacional.

En su trayectoria han recorrido distintos espacios formativos de inter-aprendizajes, con la colaboración de especialistas del Centro de Investigación y Estudios Superiores, se inicia un proyecto piloto de formación de maestros en el Diplomado de Investigación y Sistematización de Conocimientos Indígenas y Elaboración de Materiales Educativos Interculturales y Bilingües, dirigidos a docentes y estudiantes de la Universidad Pedagógica Nacional, en Chiapas, Oaxaca, Puebla y Michoacán, Así, se extiende la visión política, pedagógica y filosófica de la nueva educación para México, creando una Red del Método Inductivo Intercultural, con docentes oficiales, educadores independientes, Unión de Maestros de la Nueva Educación para México, especialistas que comparten la filosofía política de la lucha por una educación intercultural y bilingüe controlada por las comunidades y organizaciones a favor de los derechos de los pueblos indígenas.

El tipo de educación que estamos desarrollando en nuestras comunidades, familias, escuelas, es desarrollar habilidades y capacidades de vivir bien en el sistema comunitario, en relación con las actividades que se realizan en la naturaleza o territorio que habitamos, aprendemos a trabajar en la milpa, y estudiamos sobre cómo está organizada la agricultura 
tradicional que busca establecer la soberanía alimentaria, para esto todos trabajamos, niñas, niños, madres, padres, colaboramos en todo.

\section{La actividad: sembremos cacahuate}

\subsection{Territorio}

La familia trabajamos en la parcela, organizamos la actividad dependiendo del ciclo natural de las plantas, y temporada de cada especie requiere cierto tipo de climas, también sembramos en varios tipos de suelo, la tierra negra- ijk'al chabek' lum, tierra arenosa- ji'lum, tierra negra ijk'al busbus lum, en esta última es donde sembramos cacahuate porque es donde se puede arrancar fácilmente durante la cosecha.

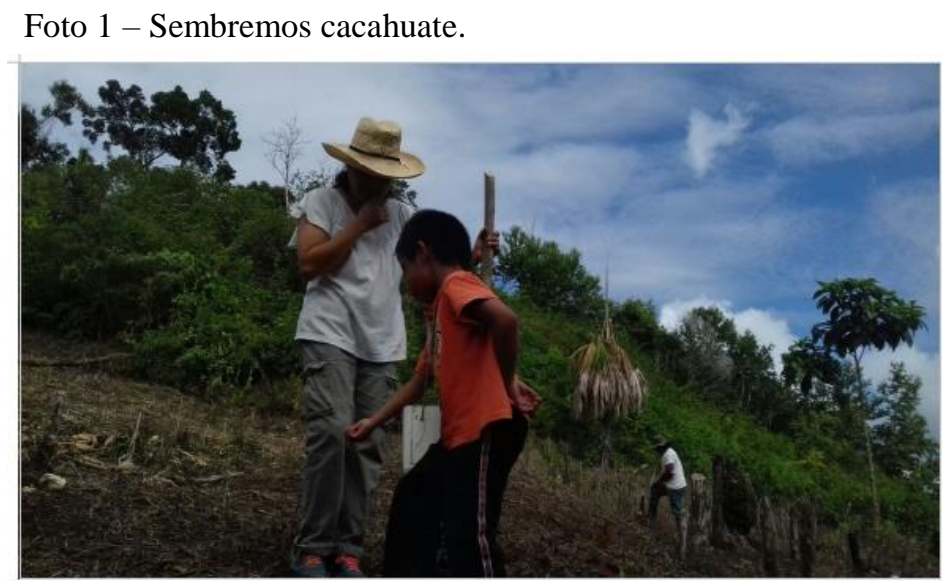

Fonte: Juan Guzmán Gutiérrez.

En la parcela hay varios cultivos, en diciembre sembramos cacahuate y también se sembró frijol porque durante su desarrollo aprovecha la lluvia de temporada, el cacahuate se desarrolla bien en ik'al busbus lum- tierra negra medio arenosa.

\subsection{Técnica}

Tecnica-Trabajo: los niños aprenden a utilizar la macana, es un instrumento de trabajo que utilizamos para perforar la tierra y depositar la semilla de cacahuates, en cada agujero de hacen aproximadamente de 20 a $30 \mathrm{~cm}$. Y se depositan de 3 a 4 semillas en cada hoyo, en esta ocasión los niños hicieron sus cultivos de cacahuate, entrenaron sus manos y vista para ubicarse espacialmente en donde van a sembrar.

Dossiê Práticas de bem viver: diálogos possíveis entre o Núcleo Takinahakỹ e Milpas Educativas 
Primero buscamos un palo de buen tamaño que se puede agarrar con el puño, se le hace punta para perforar la tierra con una profundidad entre 4 a $5 \mathrm{~cm}$.

Foto 2 - La técnica.

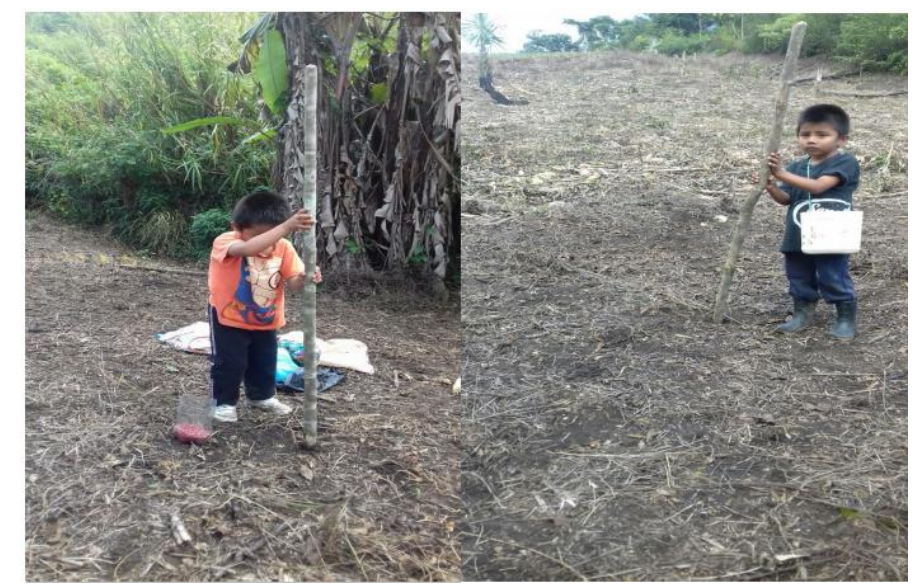

Fonte: Juan Guzmán Gutiérrez.

Aquí estamos en la milpa con mi hermano Isaías, estamos sembrando cacahuate, hacemos hoyos con un palo en donde ponemos las semillas, cada uno tenemos un bote donde llevamos las semillas y también me enseño mi papá de cómo hacerlo, fue muy divertido es un trabajo donde podemos participar (Lev Manuel Guzmán).
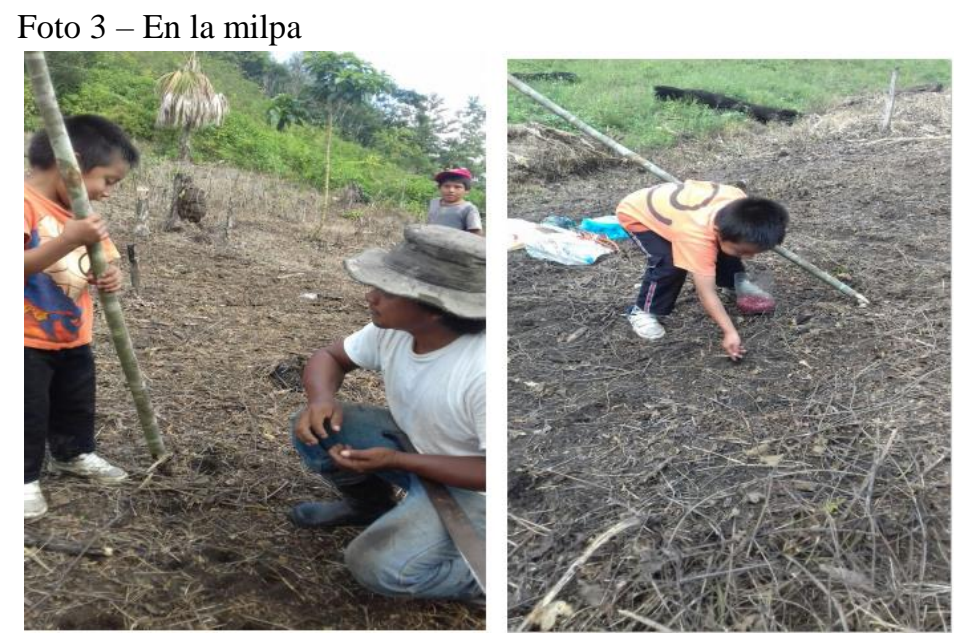

Fonte: Juan Guzmán Gutiérrez.

\subsection{Recurso}

El instrumento de trabajo se obtiene de la misma naturaleza, en la parcela. Aquí observamos diferentes y variados palos, seleccionamos uno, el que fuera más macizo. 
La semilla que sembramos es un poco silvestre, no necesita tanto barbecho, esto quiere decir que la planta se adapta en suelos y se desarrolla bastante bien sin necesidad de mecanizar el terreno. Este cacahuate es bastante rápido, es parecido al frijol, es una leguminosa que da fruto, primero florea y se entierra para desarrollar sus capsulas de cada semilla.

La vos del experto: esta variedad de cacahuate me ha gustado bastante porque se adapta muy bien en estos terrenos, se puede hacer siembra directa y no necesitamos barbechar la tierra, busque la semilla apenas me vendieron un poquito ahora ya tengo dos costales.

\subsection{Fin social}

Preservar la semilla, un hermano nos compartió parte de su semilla para sembrar, y para probar si son productivos las manos de los niños dejamos que ellos lo sembraran. Por otra parte el cacahuate cumple una función de fijar nitrógeno en el suelo, como decimos nosotros mejora la tierra a parte que lo podemos aprovechar para tostarlas y comer semillas de cacahuate.

\section{Actividad: desgranar maiz}

Foto 4 - Desgranar el maíz.

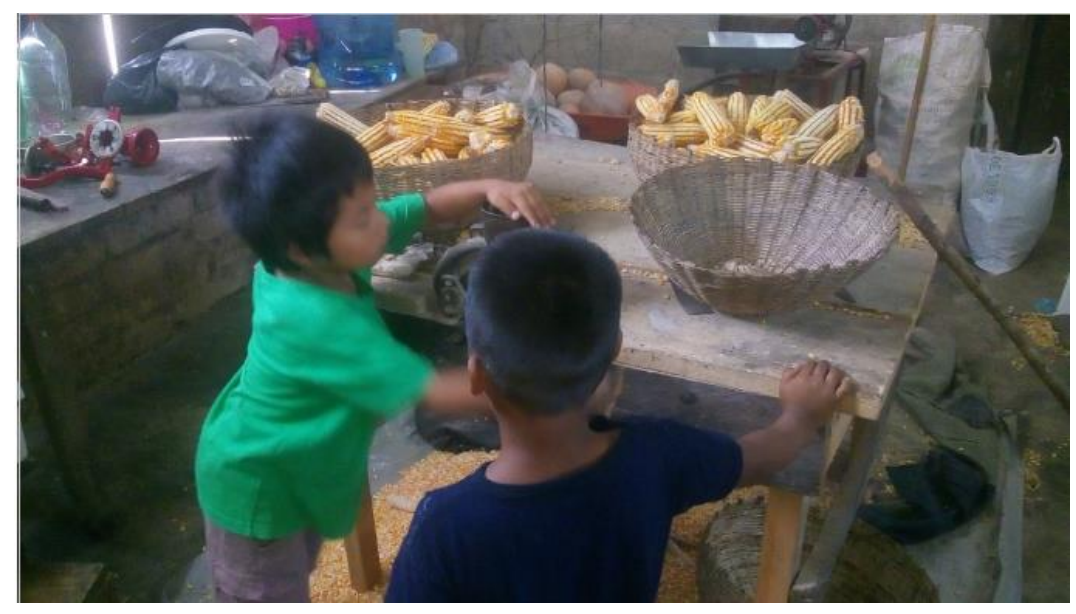

Fonte: Juan Guzmán Gutiérrez.

En diciembre se cosecha o se levantan las mazorcas de la torna milpa, todos trabajamos en la familia, en casa los niños ayudan a la mamá en el desgranado de maíz. 


\section{1 ¿Cómo desgranamos el maíz?}

Isaías: se mete la mazorca de punta y se gira el molino para que se desgrane las semillas, y sale entero el olote, sacamos los olotes abajo del tapesco.

El desgranado de maíz con la desgranadora manual es bastante divertido pero se requieres de mucha habilidad, fuerza y rapidez, los niños ensayan cuando los grandes están descansando o tomando pozol para ponerle más energía al cuerpo, en un día logramos desgranar aproximadamente de 600 a $800 \mathrm{~kg}$ con toda la familia, dos aprendices de la actividad están empezando a entender el sentido del trabajo con la vida en comunidad.

\section{2 ¿Porque desgranamos?}

Para vender maíz.

Para hacerlo en nixtamal y hacer tortillas.

Para que como el caballo.

Para hacer pozol.

También desgranamos maíz picado para darles de comer a las vacas.

Normalmente cosechamos de 40 a 50 costales de maíz en cada ciclo agrícola, desgranamos una gran parte para la venta, y dejamos otra parte para el autoconsumo, cuando vendemos el maíz recuperamos los gastos que se generan en el cultivo de la milpa, pagos de jornales en la siembra, limpia y cosecha, en 35 costales obtenemos una tonelada de granos de maíz con un costo de 5 a 6 pesos el kg.

Por otra parte no todo es por el dinero, cuando hay cosechas y están listos el maíz algunas personas se acercan a negociar por cuentas de trabajo, $100 \mathrm{~kg}$ de maíz es equivalente 5 jornales, normalmente esto funciona cuando se establece una buen confianza, la práctica de reciprocidad y ayuda mutua funciona mientras no se rompa los apoyos en el sentido equitativo del valor del trabajo con los productos obtenidos y se trabaja cuando se necesita la devolución del apoyo. 


\section{3 ¿En que parte se hace esta actividad?}

La actividad de desgranar maíz se hace en la casa, se hace temprano hasta las 3 o 4 de la tarde ya más tarde suspendemos porque el maíz está vivo, ya en la noche se puede ir el maíz, se dice que llora si se queda tirado solito.

Desde pequeño me dijeron que el maíz hay que cuidarlo bien, me contaron una historia o cuento sobre el maíz que llora, ese día fue un día muy especial porque se nos salió el caballo y fueron a comer en la milpa, desgrano muchas mazorcas de maíz, y el día siguiente fuimos a levantar uno por uno los granos de maíz para que aprendiéramos a valorar nuestro maíz. Esa noche salió la historia que está vivo en la memoria de nuestros abuelos y padres, se dice que un día regresando de la milpa ya muy tarde, caminado venían, en el camino les entro la noche, ya avían pasado cuando escucharon llorar un niño, siguieron caminando volvieron a escuchar como que llorara un niño pero están en el monte, el hombre dijo vamos a ver ¿Por qué y donde llora ese niño? No, ya vámonos puede ser un duende, el hombre no hizo caso, se regresaron a ver en el lugar que escucharon, no encontraron niño, más que unas cuantas mazorcas de maíz, puede ser el sagrado maíz, está pidiendo que lo llevemos. Guardo en su morral las mazorcas y se fueron caminando de regreso a casa, es como se supo que el maíz está vivo y llora si se queda tirado, y se va cuando tiramos las hojas ya oscuro o en la noche.

\section{4 ¿Qué tipos de maíz se desgrana?}

Maíz amarillo.

Hay maíz blanco con olote delgado.

El maíz que desgranamos esta cruzado de maíz amarillo y blanco, el maíz amarillo es más resistente al clima pero no rinde mucho, el maíz blanco se produce muy bien pero no es muy resistente se pica muy pronto por eso se hizo la cruza de las dos variedades.

\section{Actividad: vamos a pescar en el rio}

La pesca se realiza en el territorio, se identifica el donde esta profundo el rio, también se observa en donde hay peces y es ahí donde se pone la trampa. La actividad se realizó en dos momentos, primero en el rio que pasa por la comunidad, la otra en el rio que pasa por la parcela, es rio de agua dulce, aprenden a buscar sus alimentos en la naturaleza. 
Foto 5 - La pesca.

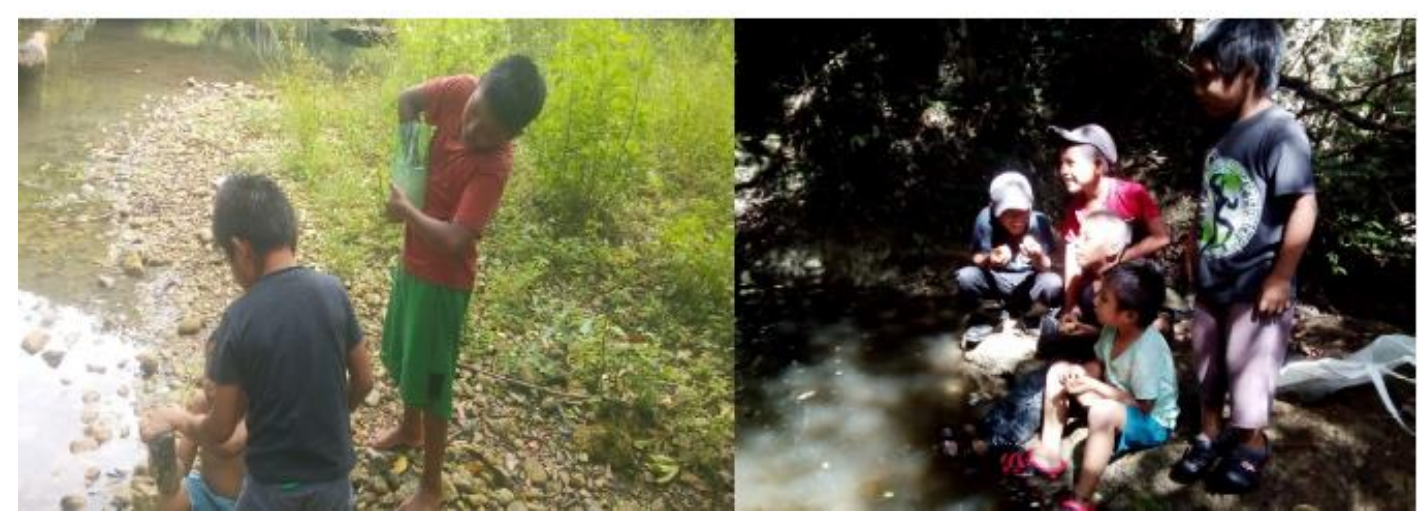

Fonte: Juan Guzmán Gutiérrez.

\subsection{Técnica}

Los niños han inventado sus propias técnicas de pesca, se corta la botella de tres Litros hasta donde está el cuello y se introduce adentro de forma invertida, se le pone comida, masa para que entren a comerlo. También se sumerge en los espacios donde está el rio un poco profundo, se deja un tiempo aproximadamente media hora y se para a revisar si ya entraron algunos, pueden entrar fácilmente pero para salir es más difícil.

\section{Foto 6 - La técnica.}

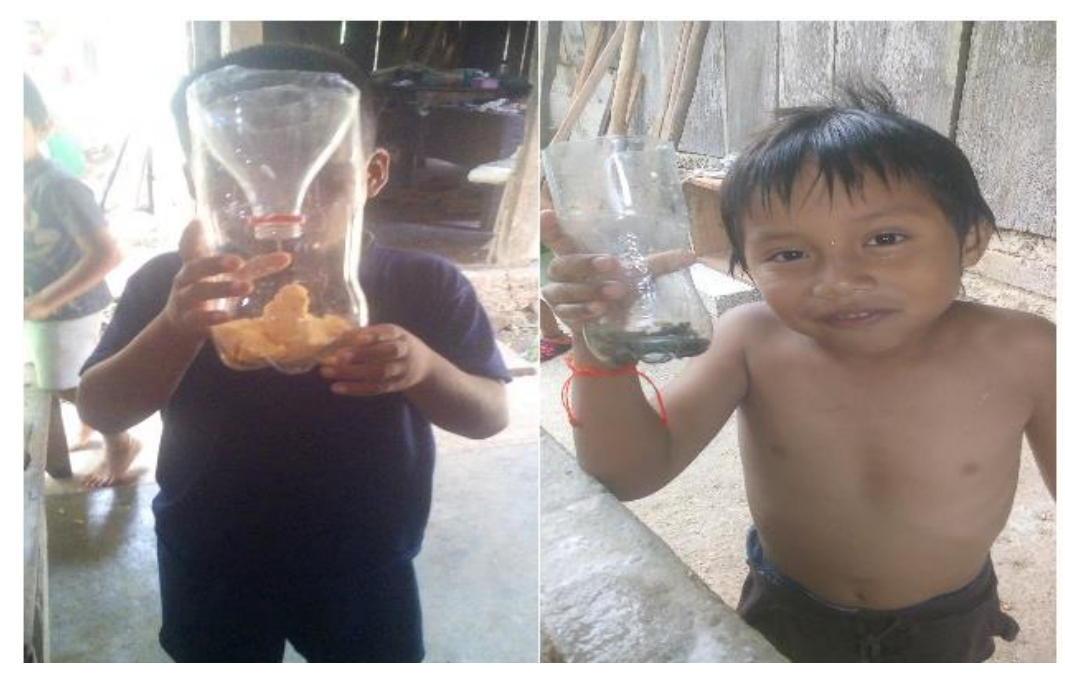

Fonte: Juan Guzmán Gutiérrez. 


\subsection{Recursos - objetos de trabajo}

Clasificación de los productos obtenidos: sardinas, charales y un bagre.

Reconocieron por sus nombres y están listos para limpiarlos y cocinarlos para la comida.

Foto 7 - Los recursos.

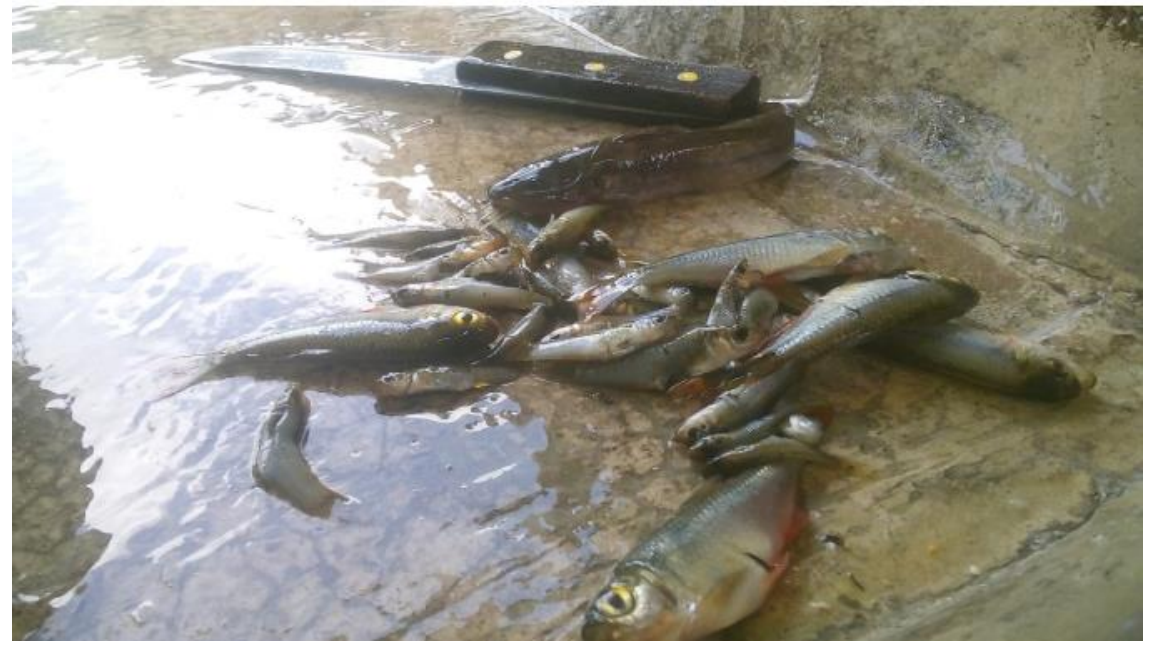

Fonte: Juan Guzmán Gutiérrez.

\subsection{Finalidad de la actividad: la alimentación, nutrición}

Foto 8 - La finalidad.

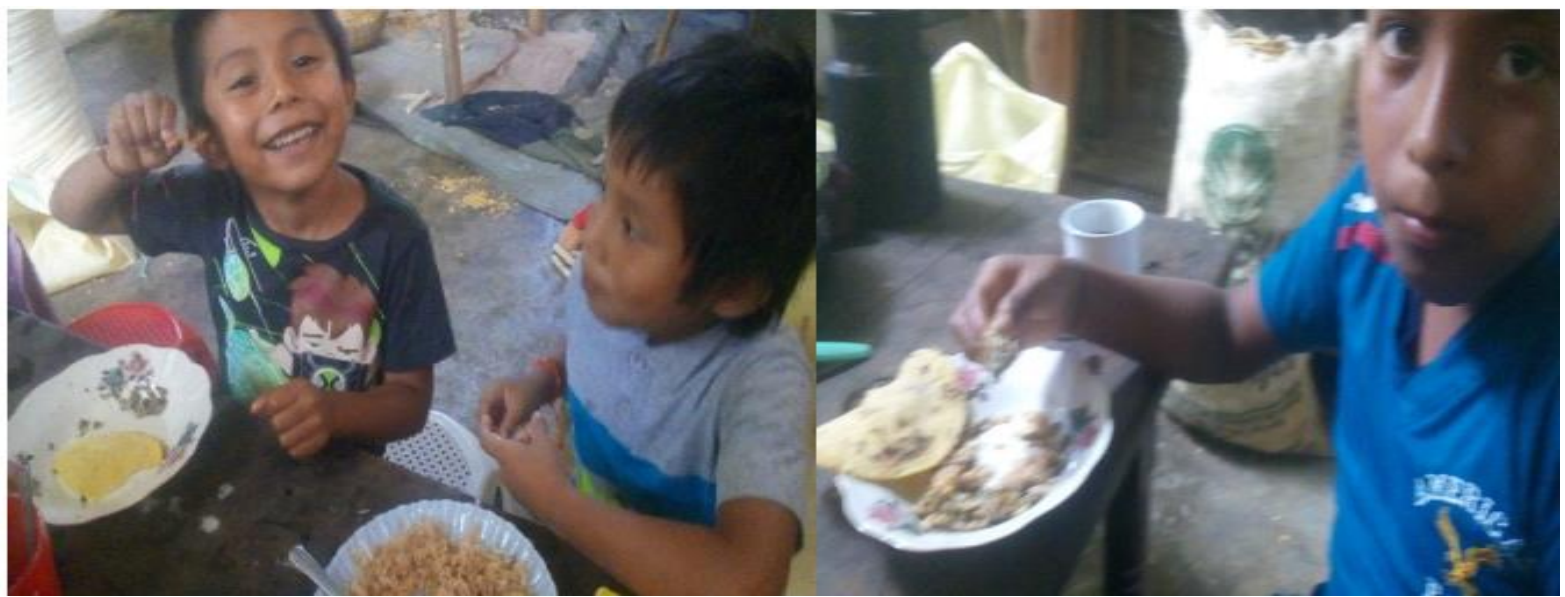

Fonte: Juan Guzmán Gutiérrez. 


\subsection{Ampliación del conocimiento}

Isaías es quien está interesado de conocer un poco más sobre la vida de los peces, saber de los diferentes ecosistemas en donde se desarrollan, se ha comprado un libro en donde se trata de los diferentes peces de agua dulce.

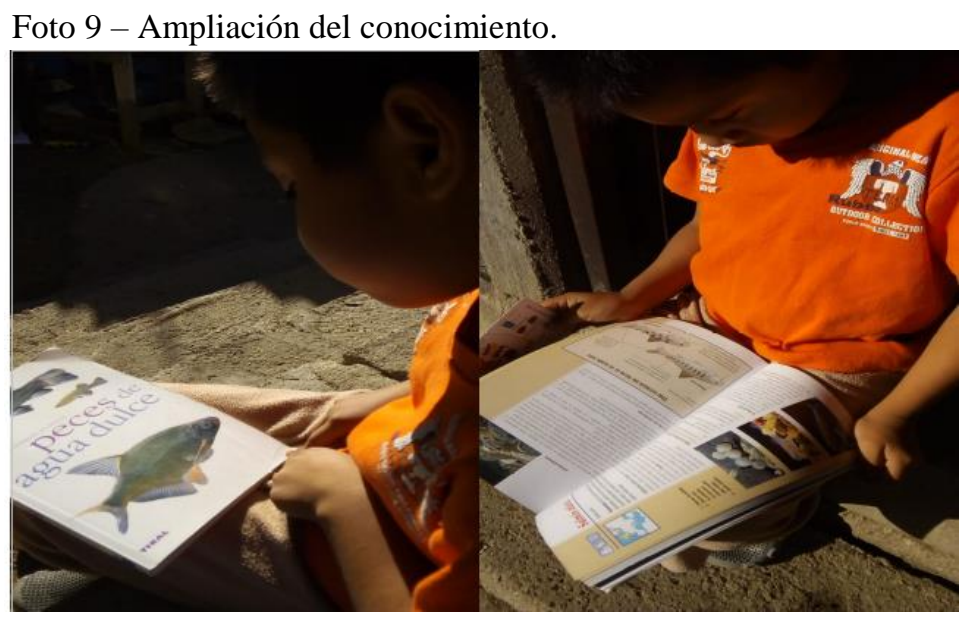

Fonte: Juan Guzmán Gutiérrez.

\subsection{Pregunta de los niños a investigar}

¿A dónde se fueron los peces si antes avían mucho?

En la actividad de la pesca nos dimos cuenta que los peces se están extinguiendo porque la comunidad vecina que es Nuevo México fueron beneficiados de un programa de gobierno sobre la construcción de agua entubada, se construyo un tanque de captación de agua en donde le aplicaron un producto químico para desinfectar el agua de consumo humano y ha provocado casi la extinción de una gran cantidad de especies de peces en el rio en donde podemos obtener nuestros alimentos. Lo que para la comunidad es un avance es destrucción en la naturaleza.

Foto 10 - La pesca.

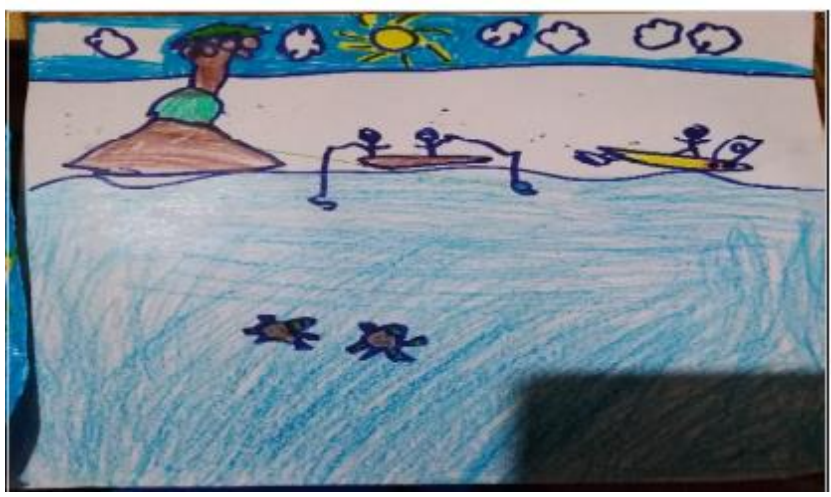

Fonte: Juan Guzmán Gutiérrez.

Dossiê Práticas de bem viver: diálogos possíveis entre o Núcleo Takinahakỹ e Milpas Educativas R. Articul.const.saber, 2019, v.4: e59295 
Este es el dibujo de Lev Manuel, representa la pesca pero donde no hay peces solamente tortugas.

Créditos: es un trabajo del proyecto de las Milpas Educativas, Financiado de la fundación Kellog's. Coordinado por Stefano Sartorello, INIDE, Unibersidad Iberoamericana, Maria Bertely del CIESAS, México.

Diseño y colaboradores:

Juan Guzmán Gutiérrez integrante de la Unión de Maestros de la Nueva Educación para México. Estudio Pedagogía en Facultad de Humanidades Campus VI, Universidad Autónoma de Chiapas. Milpero desde las raíces ancestrales del pueblo tzeltal.

Olivia Andrés Santiago. Milpera en la familia, está aprendiendo a vivir en comunidad y participa de forma voluntaria en el proyecto, trabaja en educación especial Centro de Atención Múltiple \# CAM 12. IEPO.

Niños:

Isaías Guzmán Andrés

Lev Manuel Guzmán Andrés

Eduardo Hernández Álvaro

Jerónimo Hernández Guzmán

Alan Hernández Gutiérrez

Jerónimo Hernández Álvaro

Submetido em 02 de julho de 2019.

Aceito em 08 de agosto de 2019. Publicado em 09 de agosto de 2019. 